INFO ARTIKEL

Riwayat Artikel:

Diterima : 1 Juni 2020

Disetujui : 5 Agustus 2020

\title{
GEOGRAFI
}

\section{OPTIMALISASI DATA SATELIT PENGINDERAAN JAUH UNTUK PERHITUNGAN NERACA SUMBERDAYA HUTAN KOTA BUKIT TINGGI}

\author{
Thuba Imam Fauzi ${ }^{1}$, dan Fahrezy Maulana $\mathrm{Haz}^{2}$ \\ ${ }^{1}$ Geografi, Universitas Negeri Padang \\ ${ }^{2}$ Penginderaan Jauh, Universitas Negeri Padang \\ $(\Xi)$ thubaimamfauzi@gmail.com
}

\begin{abstract}
Forest resources are natural resources that are still available and have many functions for the continuity of life. Human activities often change the function of forests so that the changes occur dynamically. The calculation of the balance of forest resources in the city of Bukit Tinggi is a tool for forest evaluation as an early warning system regarding forest degradation. This research method uses digitization, map overlay, Quick Bird imagery in 2006 and 2019. The purpose of this research will be to obtain a Forest Resources Balance Map. In 2006 the forest area was 314 ha (25.57\%), in 2011 the forest area was 308 ha (25.08\%), in 2016 the forest area was 304 ha (24.75\%), while in 2019 the area forest of 302 ha (24.59\%). Thus the average rate of forest degradation occurring in Kota Bukit Tinggi is around $0.081 \%$ year.
\end{abstract}

Keywords: Forest resource balance, land cover, forest deforestation

\begin{abstract}
ABSTRAK
Sumberdaya hutan merupakan sumberdaya alam yang masih tersedia dan memiliki banyak fungsi untuk keberlangsungan kehidupan, aktifitas manusia sering merubah fungsi hutan sehingga perubahanya terjadi secara dinamika. Perhitungan neraca sumber daya hutan kota Bukit Tinggi, menjadi alat evaluasi hutan sebagai peringatan dini (early warning system ) mengenai degradasi hutan. Metode penelitian ini menggunakan digitasi, overlay peta, citra Quick Bird tahun 2006,dan 2019.Tujuan dari penelitian akan diperoleh Peta Neraca Sumber Daya Hutan. Pada tahun 2006 luas hutan sebesar 314 ha $(25,57 \%)$, pada tahun 2011 luas hutan sebesar 308 ha ( 25,08\%), pada tahun 2016 luas hutan sebesar 304 ha $(24,75 \%)$, sedangkan pada tahun 2019 luas hutan sebesar 302 ha (24,59\%). Dengan demikian rata-rata laju degradasi hutan yang terjadi di Kota Bukit Tinggi sekitar 0,081\% pertahun.
\end{abstract}

Kata kunci : Neraca sumber daya hutan,Penutup Lahan, Deforestasi Hutan

\section{PENDAHULUAN}

Sumberdaya alam merupakan sumberdaya yang esensial bagi kelangsungan hidup manusia. Ketiadaan hak kepemilikan (property right) pada sumberdaya alam mendorong terjadinya inefisiensi dalam penggunaan sumberdaya alam. Kondisi ini juga telah menyebabkan terjadinya eksploitasi yang berlebihan dalam pemanfaatan sumberdaya alam seperti, sumberdaya alam berupa hutan.

Sumber daya hutan merupakan salah satu ciptaan Tuhan Yang Maha Kuasa yang memiliki peranan yang sangat penting dalam menjaga keseimbangan alam di jagad raya ini. Sebab di dalam hutan telah diciptakan segala makhluk hidup baik besar, kecil, maupun yang tidak dapat dilihat dengan mata. Di samping itu, di dalamnya juga hidup sejumlah tumbuhan yang menjadi hamparan, yang menjadi kesatuan yang utuh.

Hutan Indonesia terkenal sebagai hutan hujan tropis, hutan yang secara umum dikenal sebagai hutan lebat. Indonesia memiliki hutan yang sangat beragam jenisnya, mulai dari hutan primer hingga hutan mangrove. Hutan indonesia memiliki hasil 
alam yang berupa hasil hutan kayu yang dapat dijadikan sebagai bahan industri kayu, pulp, dan sebagainya. Selain hasil hutan berupa kayu Indonesia juga memiliki hasil hutan bukan kayu seperti rotan, kantong semar, madu hutan dan sebagainya. Hutan merupakan harta kekayaan alam yang diatur oleh pemerintah agar memberikan dampak positif terhadap penyediaan lapangan kerja, mendorong pengembangan wilayah, pertumbuhan ekonomi serta mempunyai peran penting sebagai sistem penyangga kehidupan dunia. Selain itu, hutan bagi masyarakat bukanlah hal yang baru melainkan salah satu sumber daya alam yang mampu menyediakan bahan-bahan kebutuhan dasar masyarakat seperti pangan, papan, obat-obatan, dan pendapatan keluarga, sehingga masyarakat mengupayakan pengelolaan hutan secara lestari agar mereka tetap bisa memanfaatkan hasil hutan di masa mendatang (Purwoko, 2002).

Pemanfaatan hutan yang tidak disertai dengan upaya pelestarian akan menimbulkan gangguan terhadap hutan seperti menurunnya produktivitas sumber daya alam hutan. Laju kerusakan hutan mencapai 1,1 juta hektar per tahun pada periode 2009-2013 yang disebabkan oleh kebakaran hutan dan semakin bertambahnya jumlah penduduk, sehingga untuk memenuhi kebutuhan hidup masyarakat mulai merambah hutan. (Forest Watch Indonesia, 2015).

Hutan di Indonesia diperkirakan mengalami penyusutan pada laju $15.000-20.000 \mathrm{Ha} /$ tahun. Luas hutan cenderung mengalami penyusutan sebagai akibat perubahan penggunaan lahan dari hutan ke pengunaan lain (permukiman, perindustrian, fasilitas perkotaan, dan sebagainya).

Kota Bukittinggi terletak pada rangkaian Bukit Barisan yang membujur sepanjang pulau Sumatra, dan dikelilingi oleh dua gunung berapi yaitu Gunung Singgalang dan Gunung Marapi. Kota ini berada pada ketinggian 909-941 meter di atas permukaan laut, dan memiliki hawa sejuk dengan suhu berkisar antara $16.1-24.9^{\circ} \mathrm{C}$. Sementara itu, dari total luas wilayah Kota Bukittinggi saat ini $\left(25,24 \mathrm{~km}^{2}\right) \quad 82,8 \%$ telah diperuntukkan menjadi lahan budidaya, sedangkan sisanya merupakan hutan lindung (BPS, 2019).
Luas hutan yang ada di Kota Bukit Tinggi sangatlah sedikit, meskipun topografi dari Kota Bukit Tinggi berbukit-bukit dan berlembahlembah, prediksinya apabila disuatu wilayah mempunyai topografi beraneka ragam, maka potensi hutan menjadi sektor yang dominan. Faktor suhu juga memprediksi bahwasanya suatu wilayah mempunyai hutan yang luas ataupun tidak bisa dilihat dari intensitas suhu yang ada, seperti halnya dataran rendah akan memiliki suhu yang tinggi diakibatkan kawasan hutan didataran rendah sangat sedikit, karena salah satu fungsi hutan adalah mendinginkan suhu bumi. Hutan menyerap karbondioksida yang merupakan salah satu sumber penyebab perubahan iklim dan pemanasan global. Hal ini berbeda dengan Kota Bukit Tinggi, walaupun terletak di daerah dataran tinggi serta memiliki suhu yang dingin berkisar $16.1-24.9{ }^{\circ} \mathrm{C}$ potensi hutanya sangat sedikit, pada tahun 2006 luas hutan kota ini adalah 314 ha, tentunya angka tersebut akan selalu berkurang dengan adanya faktor jumlah penduduk.

Peningkatan jumlah penduduk mengandung konsekuensi meningkatnya kebutuhan akan tanah, untuk tempat tinggal dan bercocok tanam yang selanjutnya untuk tempat usaha lainnya, namun di sisi lain dihadapkan pada kenyataan bahwa luas tanah tidak dapat bertambah, karenanya sasaran yang paling mudah untuk diakses adalah tanah hutan atau kawasan hutan yang ada. Hal inilah yang membuka peluang munculnya degradasi hutan di Kota Bukit Tinggi setiap tahunya.

Degradasi hutan adalah perubahan didalam hutan yang merugikan susunan atau fungsi tegakan hutan atau kawasan hutan sehingga menurunkan kemampuannya untuk menyediakan berbagai barang atau jasa (Hadiyan, 2017 mengutip Angelsen, 2010).

Hutan secara perlahan namun pasti, menyusut keberadaannya, dengan dilakukannya penebangan pohon, kawasannya dirambah dan tidak cepat melakukan penanaman kembali. Akibatnya bukan hanya habitat satwa yang terganggu namun juga ekosistem alam turut berubah secara drastis, dan pada gilirannya nanti kehidupan manusia turut terancam bahaya. Penelitian ini bertujuan untuk menghitung Neraca sumberdaya hutan Kota Bukit Tinggi Tahun 20062019. 


\section{METODE PENELITIAN}

\section{Lokasi Penelitian}

Penelitian ini dilakukan dilaukan di Kota Bukit Tinggi dengan letak astronomis yaitu $100^{\circ} 20-100^{\circ} 25$ Bujur Timur dan $00^{\circ} 16-00^{\circ} 20$ Lintang Selatan. Penelitian ini bertujuan menghitung tutupan lahan kota Bukit Tinggi Tahun 2006-2019.

\section{Alat dan bahan}

Bahan yang digunakan adalah citra Quick Bird tahun 2006, 2011,2016,dan Quick Bird tahun 2019 serta Peta Rupa Bumi Indonesia Kota Bukit Tinggi skala 1 : 50.000. Sedangkan alat yang dipakai diantaranya komputer,dll. Metode tersebut secara garis besar terdiri dari 1 proses, yaitu Sistem Informasi Geografis (SIG) dengan teknik Digitasi.

\subsection{Sistem Informasi Geografis}

Sistem ini diimplementasikan dengan perangkat keras dan perangkat lunak komputer yang berfungsi untuk akusisi dan verifikasi data, kompilasi data, penyimpanan data, perubahan dan pembaharuan data, manajemen dan pertukaran data, manipulasi data, pemanggilan dan presentasi data serta analisis data.

\subsection{Digitasi}

Digitasi adalah suatu proses mengkonversi data analog menjadi data digital dimana dapat ditambahkan atribut yang berisikan informasi dari objek yang dimaksud.

\section{Metode Pengumpulan Data}

\subsection{Metode pengumpulan data sekunder}

Peta yang diperlukan dalam penyusunan neraca sumber daya hutan antara lain :

1. Peta Aktiva dan Peta Pasiva hutan

2. Peta Administrasi Bukit Tinggi

3. Peta Interpretasi Citra

(BSN, 2014)

\section{Metode pengolahan data}

Pengolahan data potensi tegakan hutan untuk mendapatkan hubungan antara peubah langsung di potret udara (kerapatan tajuk, diameter tajuk, dan tinggi pohon) terhadap peubah tak langsung (volume tegakan) menggunakan software lotus, Minitab dan lain sebagainya untuk memperoleh suatu persamaan regresi.
Peta-peta tersebut diatas, diplot pada peta dasar sehingga menghasilkan peta Aktiva dan peta Pasiva. Peta Aktiva dan Peta Pasiva kemudian dioverlaykan untuk menghasilkan Peta Neraca Sumber Daya Hutan.

Peta Aktiva dan peta Pasiva yang dibuat secara manual kemudian didigitasi. Luas masingmasing berdasarkan fungsi hutan dan tipe hutan diperoleh dari hasil perhitungan peta digitasi.

\section{Tahapan Penelitian}

Penelitian ini terdiri dari beberapa tahap, yaitu dengan diawali tahap persiapan, pemprosesan dan pembahasan. Tahap persiapan berupa persiapan alat dan bahan yang akan digunakan dalam penelitian. Tahap pemprosesan berupa pengolahan bahan citra Quick Bird. Hasil klasifikasi dari penelitian ini menggunakan metode digitasi, yang mana akan menghasilkan informasi penutupan lahan. Tahap terakhir yaitu pembahasan,berupa menganalisa hasil peta yang telah dilakukan pengerjaanya.

\section{HASIL DAN PEMBAHASAN}

\section{Neraca Sumberdaya Hutan}

Peta neraca hutan wilayah Kota Bukit Tinggi, diperoleh dari hasil overlay antara Peta Tutupan Lahan 2006, dengan Peta Tutupan Lahan 2019. Pada peta tersebut,diperoleh informasi mengenai kondisi cadangan awal,pemanfaatn,dan kerusakan yang terjadi serta saldo akhir pada tahun 2019 (Tabel 1). Selama periode 13 tahun (Tahun 20062019) terjadi pengurangan hutan 12 ha $(0,081 \%)$ dari luas hutan. Pada tahun 2006 luas hutan sebesar 314 ha $(25,57 \%)$, pada tahun 2011 luas hutan sebesar 308 ha (25,08\%), pada tahun 2016 luas hutan sebesar 304 ha $(24,75 \%)$, sedangkan pada tahun 2019 luas hutan sebesar 302 ha $(24,59$ $\%)$.

Perubahan tutupan lahan didefinisikan sebagai bergesernya jenis tutupan lahan dari satu tipe ke tipe lainnya baik bertambah maupun berkurangnya dari waktu ke waktu atau berubahnya fungsi suatu lahan pada waktu yang berbeda (Achmad, 2020 mengutip Diyono 2001). Perubahan penutupan lahan yang dianalisis pada penelitian ini dibatasi pada tahun 2006, 2011, 2016,dan 2019. Hal ini dilakukan untuk menghasilkan data yang signifikan setelah sekian 
lama berlangsungnya pembangunan di Kota Bukit Tinggi.

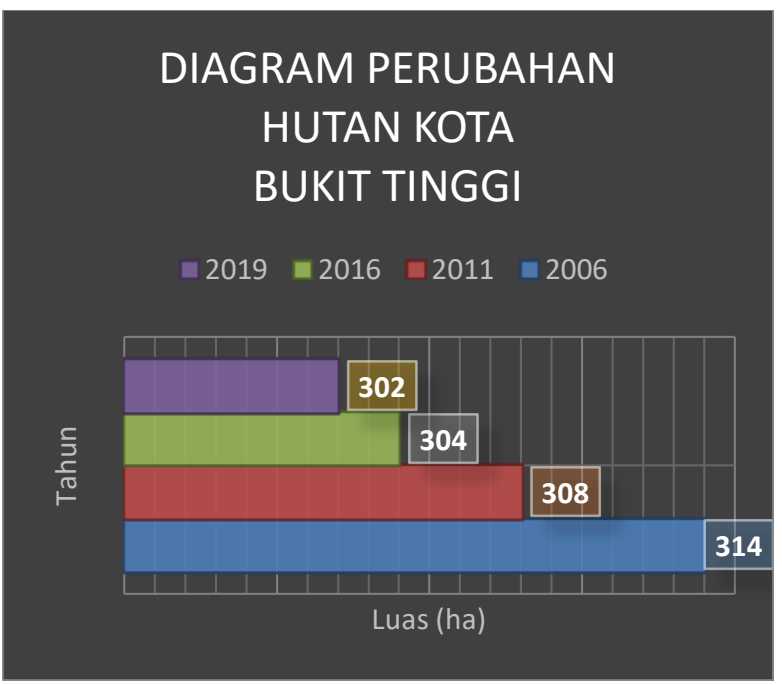

Gambar 1. Diagram perubahan hutan kota Bukit



Gambar 2. Peta neraca sumberdaya hutan kota Bukit Tinggi 2006-2019

(Sumber : Analisis Data, 2019)

Berikut tabel tingkat degradasi hutan setiap tahun penelitian.

Tabel 2. Perubahan tutupan lahan 2006-2011

\begin{tabular}{|c|c|c|c|c|}
\hline \multirow{2}{*}{ Tahun } & \multicolumn{2}{|c|}{ Tutupan Lahan } & \multicolumn{2}{c|}{ Perubahan } \\
\cline { 2 - 5 } & Luas(ha) & $\%$ & Luas(ha) & $\%$ \\
\hline 2006 & 314 & 50,48 & 0,00965 & 0,965 \\
\hline
\end{tabular}

(Sumber : Analisis Data, 2019)

Tabel 1. Tutupan lahan hutan tahun 2006, 2011, 2016, dan 2019

\begin{tabular}{|c|c|c|c|c|}
\hline \multirow{2}{*}{ Tahun } & \multicolumn{2}{|c|}{ Tutupan Lahan } & \multicolumn{2}{c|}{ Perubahan } \\
\cline { 2 - 3 } & Luas(ha) & $\%$ & Luas(ha) & $\%$ \\
\hline 2006 & 314 & 25,57 & & \\
\hline 2011 & 308 & 25,08 & \multirow{2}{*}{0,00977} & 0,081 \\
\hline 2016 & 304 & 24,75 & & \\
\hline 2019 & 302 & 24,59 & 0,00081 & \\
\hline Jumlah & 1228 & 100 & & \\
\hline
\end{tabular}

(Sumber : Analisis Data, 2019) 


\begin{tabular}{|c|c|c|c|c|}
\hline \multirow{2}{*}{ Tahun } & \multicolumn{2}{|c|}{ Tutupan Lahan } & \multicolumn{2}{c|}{ Perubahan } \\
\cline { 2 - 3 } & Luas(ha) & $\%$ & Luas(ha) & $\%$ \\
\hline 2016 & 304 & 50.16 & & \\
\hline 2019 & 302 & 49,83 & 0,0033 & 0,33 \\
\hline Jumlah & 606 & 100 & 0,00028 & \\
\hline
\end{tabular}

(Sumber : Analisis Data, 2019)

Kegiatan interpretasi citra QuickBird yang telah dilakukan menghasilkan informasi mengenai luas hutan disetiap tahun penelitianya. Berikut infromasi yang dihasilkan mengenai luas hutan kecamatan di Kota Bukit Tinggi. Luas hutan pada tahun 2006 secara keseluruhan adalah 314 ha, dengan pembagian luas hutan perkecamatan, yaitu : Kecamatan Aur Birugo memiliki luas 32 ha atau $10,19 \%$, kecamatan Guguk Panjang memiliki luas 107 ha atau 34,07 \%, dan kecamatan Mandiangin memiliki luas 175 ha atau 55,73\%. Luas hutan pada tahun 2011 secara keseluruhan adalah 308 ha, dengan pembagian luas hutan perkecamatan, yaitu : Kecamatan Aur Birugo memiliki luas 30 ha atau 9,74\%, kecamatan Guguk Panjang memiliki luas 105 ha atau $34,09 \%$, dan kecamatan Mandiangin memiliki luas 173 ha atau 56,16\%. Luas hutan pada tahun 2016 secara keseluruhan adalah 304 ha, dengan pembagian luas hutan perkecamatan, yaitu : Kecamatan Aur Birugo memiliki luas 30 ha atau 9,74\%, kecamatan Guguk Panjang memiliki luas 101 ha atau 33,22 $\%$, dan kecamatan Mandiangin memiliki luas 173 ha atau 56,16\%. \%. Luas hutan pada tahun 2019 secara keseluruhan adalah 302 ha, dengan pembagian luas hutan perkecamatan, yaitu : Kecamatan Aur Birugo memiliki luas 29 ha atau 9,6\%, kecamatan Guguk Panjang memiliki luas 101 ha atau 33,44\%, dan kecamatan Mandiangin memiliki luas 172 ha atau 56,95\%.

Tabel 4. Luas hutan kecamatan tahun 2006

\begin{tabular}{|c|c|c|}
\hline \multirow{2}{*}{ Kecamatan } & \multicolumn{2}{|c|}{2006} \\
\cline { 2 - 3 } & Luas (ha) & $\%$ \\
\hline Aur Birugo & 32 & 10,19 \\
\hline Guguk Panjang & 107 & 34,07 \\
\hline Mandiangin & 175 & 55,73 \\
\hline
\end{tabular}

\begin{tabular}{|c|c|c|}
\hline \multirow{2}{*}{ Kecamatan } & \multicolumn{2}{|c|}{2006} \\
\cline { 2 - 3 } & Luas (ha) & $\%$ \\
\hline Jumlah & 314 & 100 \\
\hline
\end{tabular}

(Sumber : Analisis Data, 2019)

Tabel 5. Luas hutan kecamatan tahun 2011

\begin{tabular}{|c|c|c|}
\hline \multirow{2}{*}{ Kecamatan } & \multicolumn{2}{|c|}{2011} \\
\cline { 2 - 3 } & Luas (ha) & $\%$ \\
\hline Aur Birugo & 30 & 9,74 \\
\hline Guguk Panjang & 105 & 34,09 \\
\hline Mandiangin & 173 & 56,16 \\
\hline Jumlah & 308 & 100 \\
\hline
\end{tabular}

(Sumber : Analisis Data, 2019)

Tabel 6. Luas hutan kecamatan tahun 2016

\begin{tabular}{|c|c|c|}
\hline \multirow{2}{*}{ Kecamatan } & \multicolumn{2}{|c|}{2016} \\
\cline { 2 - 3 } & Luas (ha) & $\%$ \\
\hline Aur Birugo & 30 & 9,74 \\
\hline Guguk Panjang & 101 & 33,22 \\
\hline Mandiangin & 173 & 56,16 \\
\hline Jumlah & 304 & 100 \\
\hline
\end{tabular}

(Sumber : Analisis Data, 2019)

Tabel 7. Luas hutan kecamatan tahun 2019

\begin{tabular}{|c|c|c|}
\hline \multirow{2}{*}{ Kecamatan } & \multicolumn{2}{|c|}{2019} \\
\cline { 2 - 3 } & Luas (ha) & $\%$ \\
\hline Aur Birugo & 29 & 9,6 \\
\hline Guguk Panjang & 101 & 33,44 \\
\hline Mandiangin & 172 & 56,95 \\
\hline Jumlah & 302 & 100 \\
\hline
\end{tabular}

(Sumber : Analisis Data, 2019)

Dari hasil analisa diatas maka kecamatan yang memiliki luas hutan terbesar disetiap tahun penelitian adalah kecamatan Mandiangin, lalu 
kecamatan Guguk Panjang, dan kecamatan terakhir Aur Birugo. Berikut diagram luas hutan setiap tahun penelitian

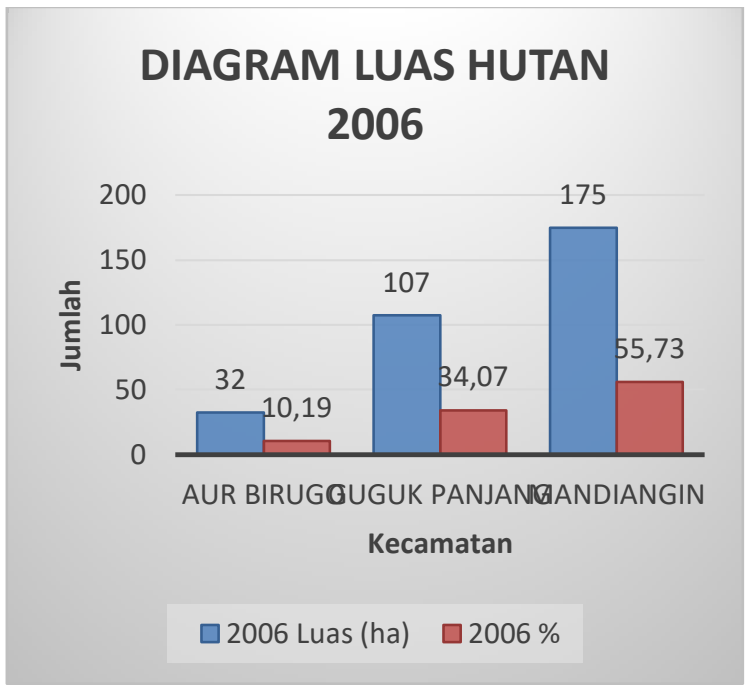

Gambar 3. Diagram luas hutan kecamatan 2006

(Sumber : Analisis Data, 2019)



Gambar 4. Diagram luas hutan kecamatan 2011 (Sumber : Analisis Data, 2019)

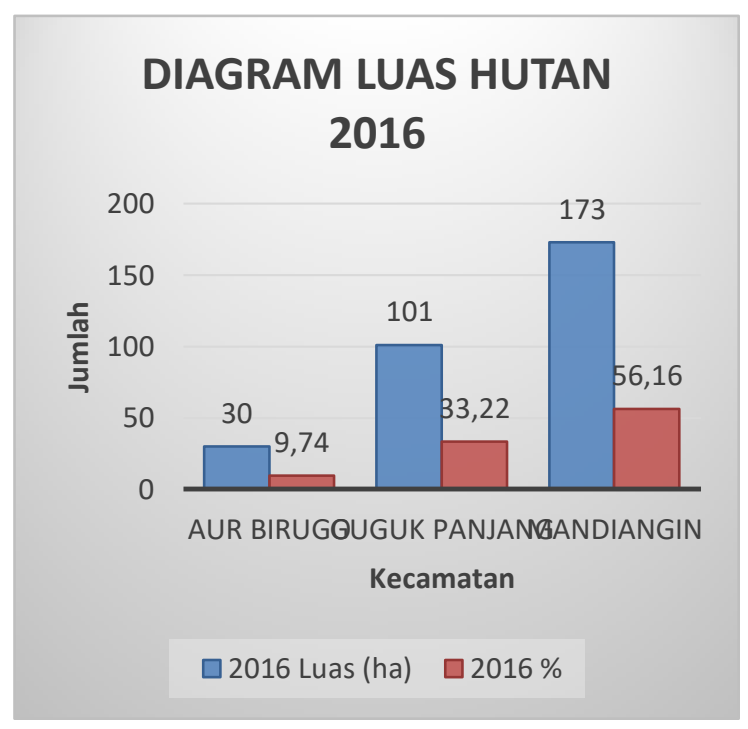

Gambar 5. Diagram luas hutan kecamatan 2016 (Sumber : Analisis Data, 2019)

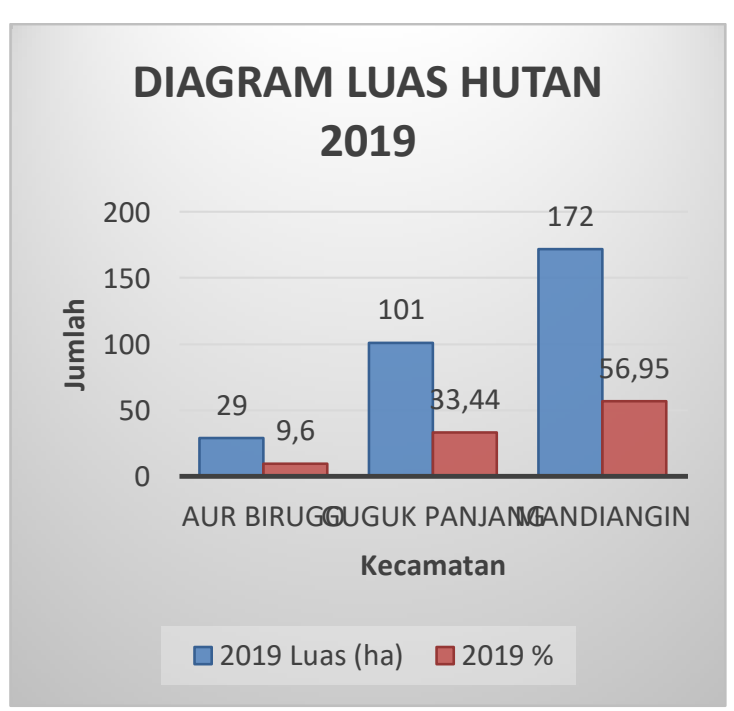

Gambar 6. Diagram Luas Hutan 2019 (Sumber : Analisis Data, 2019) 


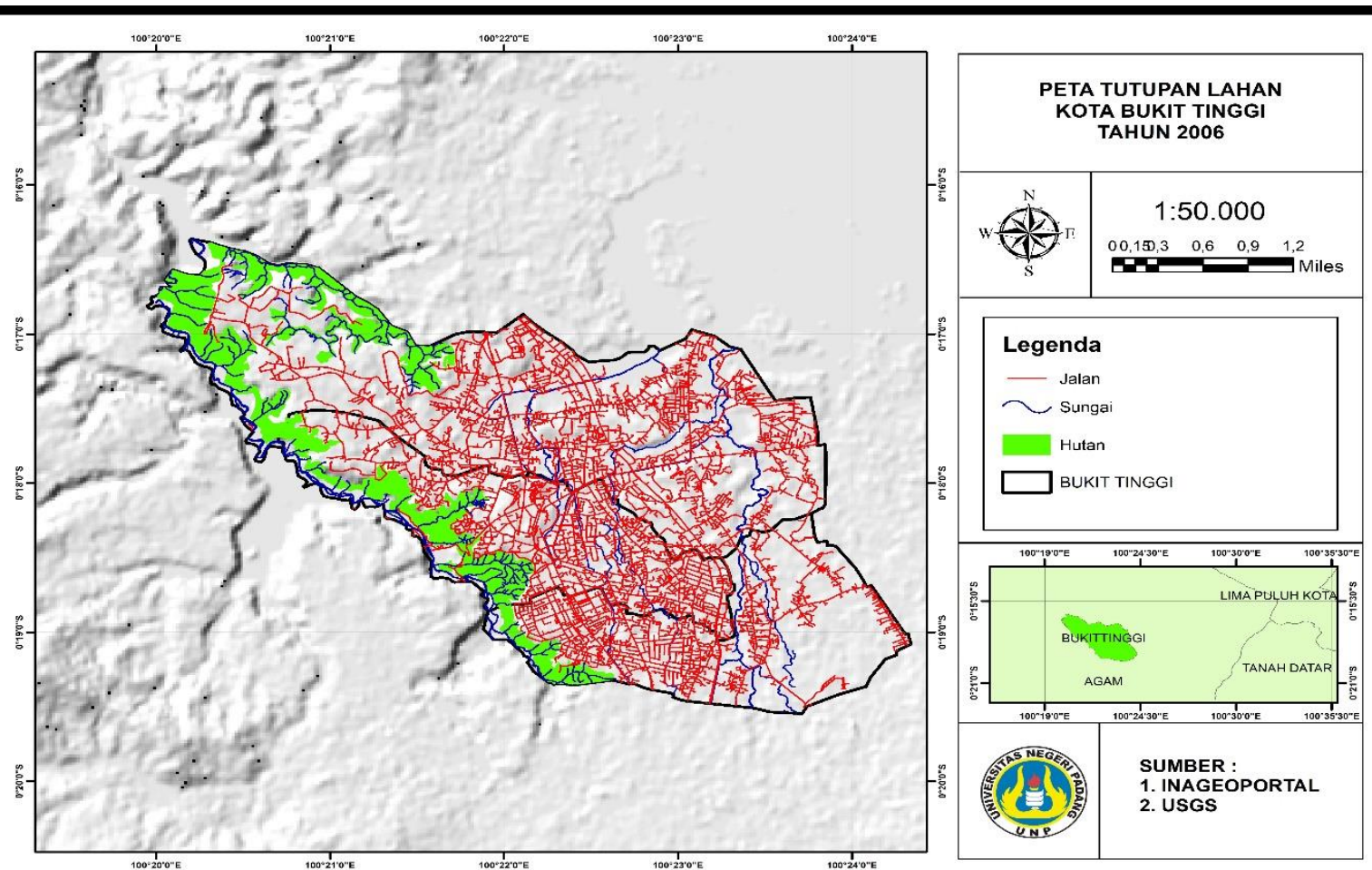

Gambar 7. Peta tutupan lahan kota Bukit Tinggi 2006

(Sumber : Analisis Data, 2019)

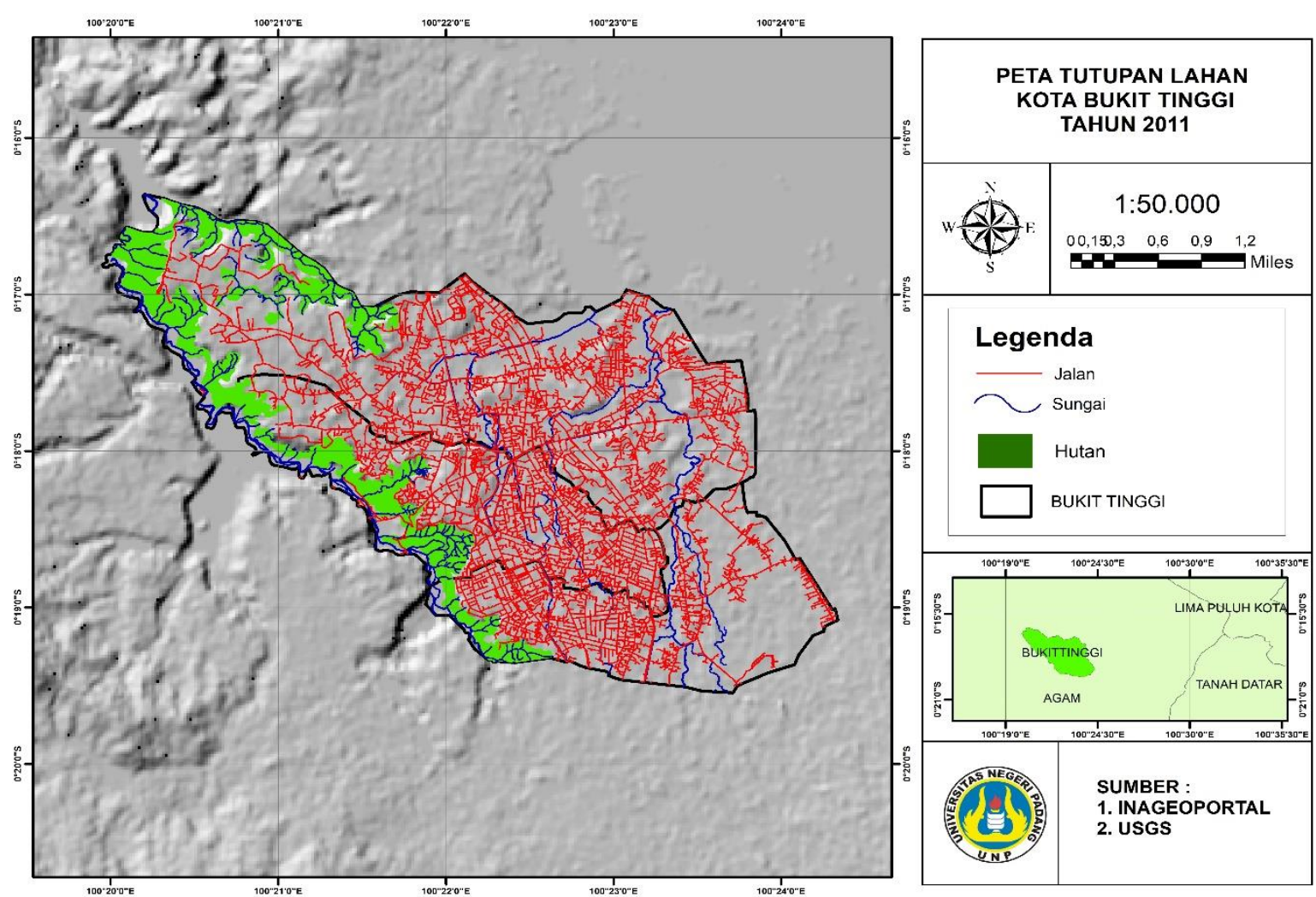

Gambar 8. Peta tutupan lahan kota Bukit Tinggi 2011

(Sumber : Analisis Data, 2019) 


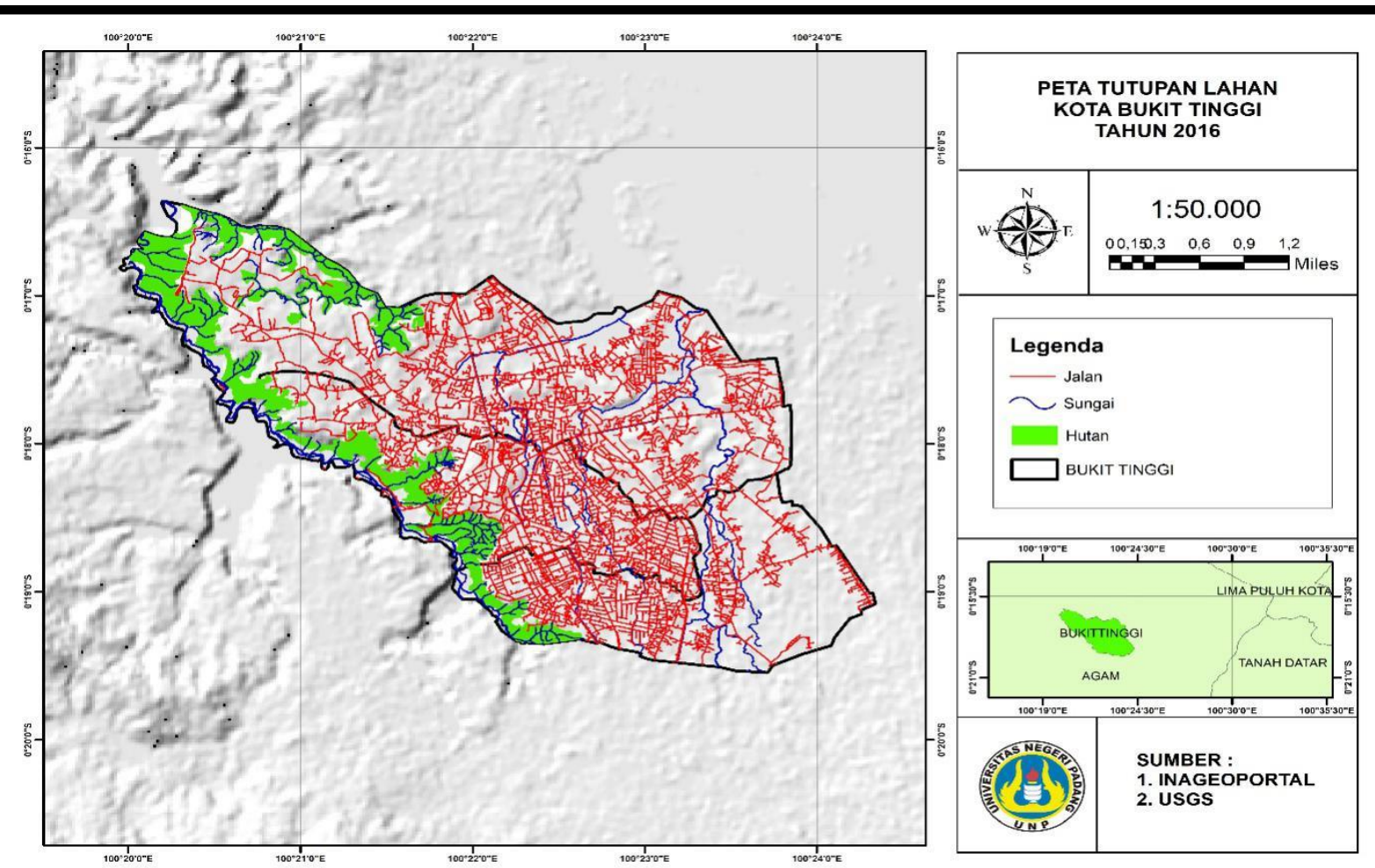

Gambar 9. Peta tutupan lahan kota Bukit Tinggi 2016

(Sumber : Analisis Data, 2019)


Gambar 10. Peta tutupan lahan kota Bukit Tinggi 2019

(Sumber : Analisis Data, 2019)

\section{Degradasi Hutan kota Bukit Tinggi}

Hutan yang terdegradasi adalah hutan yang telah mengalami kerusakan sampai pada suatu point/titik dimana penebangan kayu maupun non kayu pada periode yang akan datang menjadi tertunda atau terhambat semuanya. Sedangkan sebagian lainnya mendefinisikan hutan yang terdegradasi sebagai suatu keadaan dimana fungsi ekologis, ekonomis dan sosial hutan tidak terpenuhi. Sedangkan menurut (Oldeman, 1992) mengatakan bahwa degradasi adalah suatu proses dimana terjadi penurunan kapasitas baik saat ini 
maupun masa mendatang dalam memberikan hasil (product).

Tabel 8. Hasil Perubahan Lahan

\begin{tabular}{|c|c|c|c|c|}
\hline \multirow{2}{*}{ Tahun } & \multicolumn{2}{|c|}{ Tutupan Lahan } & \multicolumn{2}{|c|}{ Perubahan } \\
\cline { 2 - 3 } & Luas(ha) & $\%$ & Luas(ha) & $\%$ \\
\hline 2006 & 314 & 25,57 & & \\
\hline 2011 & 308 & 25,08 & 0,00977 & \multirow{2}{*}{0,081} \\
\hline 2017 & 304 & 24,75 & & \\
\hline 2019 & 302 & 24,59 & 0,00081 & \\
\hline Jumlah & 1228 & 100 & & \\
\hline
\end{tabular}

(Sumber : Analisis Data, 2019)

Tabel diatas telah memberikan informasi bahwasanya laju degradasi hutan kota Bukit Tinggi sebesar 0,00081 ha atau $(0,081 \%)$ setiap tahunya. Angka tersebut diperoleh dari perubahan tutupan lahan hutan dari tahun 2006-2019 dengan perubahan 12 ha atau $(0,977 \%)$. Perubahan yang sedikit itu dipengaruhi oleh faktor, yaitu 1. kondisi topografi kota Bukit Tinggi yang cenderung berbukit dan berlembah,sehingga menyulitkan untuk dilakukan perubahan kawasan hutan.

\section{KESIMPULAN}

Perubahan selama periode 13 tahun (Tahun 2006-2019) terjadi pengurangan hutan 12 ha $(0,081 \%)$ dari luas hutan. . Pada tahun 2006 luas hutan sebesar 314 ha $(25,57 \%)$, pada tahun 2011 luas hutan sebesar 308 ha ( 25,08\%), pada tahun 2016 luas hutan sebesar 304 ha (24,75\%), sedangkan pada tahun 2019 luas hutan sebesar 302 ha $(24,59 \%)$.

Laju degradasi hutan kota Bukit Tinggi sebesar 0,00081 ha atau $(0,081 \%)$ setiap tahunya. Angka tersebut diperoleh dari perubahan tutupan lahan hutan dari tahun 2006-2019 dengan perubahan 12 ha atau $(0,977 \%)$. Perubahan yang sedikit itu dipengaruhi oleh faktor, yaitu 1 . kondisi topografi kota Bukit Tinggi yang cenderung berbukit dan berlembah,sehingga menyulitkan untuk dilakukan perubahan kawasan hutan.

Degradasi hutan membawa dampak yang besar pada keanekaragaman hayati. Hutan yang terdegradasi akan sulit dipulihkan, karena struktur tanahnya mengalami kerusakan. Hilangnya tumbuh-tumbuhan menyebabkan lahan terbuka, sehingga mudah tererosi, dan tidak dapat lagi menahan banji serta berbagai bencana lainya.

\section{DAFTAR PUSTAKA}

Achmad, E., Hamzah, H., Albayudi, A., \& Priambodo, P. (2020). Analisis Perubahan Tutupan Lahan Pada Zonasi Pengelolaan Taman Nasional Bukit Tiga Puluh Menggunakan Citra Landsat . Jurnal Hutan Tropis, 8(2), 172-184.

Badan Pusat Statistik. 2019. Kota Bukit Tinggi dalam Angka 2019.

Badan Standardisasi Nasoinal (BSN), 2014. Metode Perhitungan Tutupan Hutan Berdasarkan Hasil Penafsiran Citra Penginderaan Jauh Optik Secara Visual. Gd. Manggala Wanabakti, Jakarta.

Hadiyan, Y., Yuliah, Y., \& Pambudi, H. (2017, October). Memahami dan Membangun Pendekatan Penyelesaian Deforestasi dan Degradasi Hutan di Region Sumatera dan Kalimantan. In Proceeding Biology Education Conference: Biology, Science, Enviromental, and Learning (Vol. 14, No. 1, pp. 166-169).

Indonesia, F. W. (2015). Intip Hutan. Bogor (ID): Forest Watch Indonesia.

Oldeman LR. 1992. Global extent of soil degradation. ISRIC Bi-Annual Report19911992 p.19-36. https://edepot.wur. nl/299739. 10 Desember 2019.

Purwoko, A. (2002). Kajian akademis hutan kemasyarakatan. Medan : Fakultas Pertanian USU 